BMJ Open

Sport \&

Exercise

Medicine

\title{
Echocardiographic measurements of aortic root diameter (ARD) in collegiate football Athletes at pre-participation evaluation
}

Fred Reifsteck, ${ }^{\oplus}$ James R Clugston, ${ }^{2}$ Stephen Carek, ${ }^{2}$ Kimberly G Harmon, ${ }^{3}$ Breton Michael Asken, ${ }^{4}$ Michael C Dillon, ${ }^{5}$ Joan Street, ${ }^{6}$ Katherine M Edenfield ${ }^{\odot 2}$

To cite: Reifsteck F, Clugston JR, Carek S, et al. Echocardiographic measurements of aortic root diameter (ARD) in collegiate football Athletes at preparticipation evaluation. BMJ Open Sport \& Exercise Medicine 2019;5:e000546. doi:10.1136/ bmjsem-2019-000546

Accepted 10 May 2019

\section{(c) Author(s) (or their} employer(s)) 2019. Re-use permitted under CC BY-NC. No commercial re-use. See rights and permissions. Published by BMJ.

'University Health Center, University of Georgia Athletic Association, University of Georgia, Athens, Georgia, USA ${ }^{2}$ Community Health and Family Medicine, University of Florida, Gainesville, Florida, USA

${ }^{3}$ Family Medicine and Orthopaedics and Sports Medicine, University of Washington, Seattle, Washington, USA

${ }^{4}$ Clinical and Health Psychology, University of Florida, Gainesville, Florida, USA

${ }^{5}$ The Cardiac and Vascular Institute, Gainesville, Florida, USA

${ }^{6}$ Student Health Care Center, University of Florida, Gainesville, Florida, USA

Correspondence to Dr Fred Reifsteck; freifsteck@uhs.uga.edu

\section{ABSTRACT}

Background Some remodelling of the aortic root may be expected to occur with exercise but can already vary due to different body sizes, compositions and genetic predispositions. Attributing the cause of borderline aortic root diameter (ARD) values to either physiological or pathological conditions in American college football athletes is difficult as there is very limited normal reference values in this population. Body surface area (BSA) specific norms are thought to be useful in other cardiac measurements of football athletes.

Methods A retrospective cohort review of preparticipation examination (PPE) transthoracic echocardiogram data from collegiate football athletes was performed. ARD was analysed by field position (linemen, $n=137$; non-linemen, $n=238$ ), race (black, $n=216$; white, $\mathrm{n}=158$ ) and BSA for predictive value and associations. Values were compared with non-athlete norms, and collegiate football athlete-specific normal tables were created.

Results Only $2.7 \%$ of football athletes had ARD measurements above normal non-athlete reference values and the mean athlete ARD values were lower than nonathlete values. No athletes had an aortic root $>40 \mathrm{~mm}$ or were disqualified due to underlying cardiac pathology. Univariate analyses indicated linemen position and increasing BSA was associated with larger values for ARD. BSA outperformed race in predicting ARD. Normal tables were created for ARD stratified by BSA group classification (low, average and high BSA). Proposed clinical cut-offs for normal and abnormal values are reported for raw echocardiograph metrics and their BSA indexed scores. Conclusions Non-athlete reference values for ARD appear applicable for defining upper limits of normal for most collegiate football athletes. BSA-specific normal values may be helpful in interpreting results for athletes that exceed non-athlete norms.

\section{INTRODUCTION}

Participation in American style football (ASF) at the collegiate level requires a pre-participation evaluation (PPE). Institutions have traditionally performed history and physical examinations but many are now also

\section{What are the new findings?}

Non-athlete reference values for aortic root diameter (ARD) may be applicable for defining upper limits of normal in most collegiate football players, as the

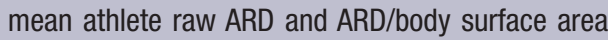
(BSA) index scores in our cohort were actually lower than previously published non-athlete values.

- BSA should be considered when interpreting ARD values at or exceeding the upper limits of normal in athletes, as we found it to have the most significant association.

- Previously defined values for ARD in an older and professional athlete population are larger than our study population and may not be applicable to college-aged football athletes.

including non-invasive cardiac testing such as ECG and echocardiogram. ${ }^{1}$ PPEs aim to uncover potentially serious or life threatening health conditions, and history and physical alone are generally not sensitive enough for undetected cardiac conditions. ${ }^{2}$ The use of these non-invasive tests may add to the sensitivity and specificity of the evaluation if appropriate normal reference values are available. Non-athlete norms may not apply to collegiate ASF (C-ASF) athletes, as non-pathologial adaptation and remodelling of the heart frequently occur with athletic activity and these C-ASF athletes tend to have larger body surface area (BSA) than most people.

There are limited data regarding aortic root dimension of ASF players. Strength sports, such as ASF, which utilise static anaerobic exercise in certain positions, may increase the degree of aortic remodelling and dilation. The extent of aortic remodelling in athletes is not completely understood, especially for ASF players who typically have high training demands and increased BSA. 
Historically, an aortic root diameter (ARD) $>40 \mathrm{~mm}$ represents a cut-off for disqualification from high-intensity exercise and evaluation for underlying connective tissue disorders, such as Marfan's syndrome. ${ }^{3}$ It is well established that the evaluation of aortic root dimensions should consider age as well as anthropometric variables, such as height and BSA, in non-athletic populations. ${ }^{4}{ }^{5}$ Pelliccia et al suggest that the most haemodynamically intense endurance disciplines, such as cycling and swimming, are associated with a mild increase in aortic dimension. ${ }^{6}$ However, these increases in aortic root dimensions are small and fall within the established limits for the general population. Additional studies have supported the use of BSA as a strong determinant of aortic dimensions. ${ }^{7-9}$ Sports with extremes of BSA and height, such as basketball and volleyball, have shown a higher prevalence of athletes with aortic roots $>40 \mathrm{~mm}$ than most athletic populations but have demonstrated a plateau of aortic dimensions at the uppermost of height and BSA. ${ }^{1011}$

Understanding the sport-specific cardiac structural findings in ASF players is important to better utilise echocardiographic screening while avoiding unnecessary testing or disqualification of athletes.

We sought to contribute echocardiographic reference values for ARD at the sinus of Valsalva in C-ASF athletes at the time of their PPE. We examined this value due to its association with cardiac conditions which can predispose to sudden cardiac death such as Marfan's syndrome and aortic root aneurysm/dissection and the ability to view it easily with echocardiogram. We also sought to determine the applicability of current non-athlete echo norms to our sample.

\section{METHODS}

Transthoracic echocardiographic data from ASF athletes in the University of Florida Athletic Association Cardiac Databank collected between 2012 and 2017 was combined with similar, de-identified data from the University of Georgia collected between 2010 and 2015. All studies were performed as part of routine PPE at the time of athlete matriculation.

Most studies $(>60 \%)$ were performed in mass by Athletic Heart, LLC ${ }^{12}$ during screening days held at each institution. Athletes who missed these screening days had echocardiograms performed on a GE Vivid E9 echocardiography machine with an M5 cardiac probe at each institution's designated cardiology office. All echocardiograms were read by cardiologists at the athlete's institution. Twelve different cardiologists contributed to interpreting these studies with the breakdown of percentage read by each as follows: $49 \%, 35 \%, 9 \%, 2 \%, 2 \%$ and seven cardiologists each reading $<1 \%$ of total studies. Routine values were measured from a parasternal long-axis view as per American Society of Echocardiography guidelines. ${ }^{13}$ Measurements were calculated initially by the echocardiographic technicians at the time of the study, with the interpreting cardiologist making corrections as needed before the final results were reported.

Our overall sample included 375 male C-ASF athletes, of which 340 had ARD measurements. The 35 participants without ARD data did not differ from the other athletes included in the analyses on any demographic factor. Height and weight were measured at the time of PPE. Race and position played were noted for each subject. The race of the athletes was self-reported in the majority of cases but if unavailable it was determined by the investigators through review of publicly available photographic roster information. ${ }^{14}{ }^{15}$ Subgroup analysis of race was confined to Black and White athletes, as there was only 1 athlete in the data set of another race. Position played was classified as linemen (offensive/defensive guard, offensive/defensive tackle, centre, defensive end or tight end) or non-linemen (running back, receiver, quarterback, linebacker, cornerback, safety, punter, kicker) and determined in most cases by athlete report at the time of their PPE or, if unavailable, by review of publicly available roster listings. ${ }^{1415}$

The primary outcome variable was ARD at the sinus of Valsalva, measured in $\mathrm{mm}$. Predictor variables of interest included player position (position: dichotomised as linemen and non-linemen), race status (race: Black and White), heart rate (HR), left ventricular ejection fraction (LVEF) and BSA $\left(\mathrm{m}^{2}\right)$ calculated as the square root of (height in $\mathrm{cm} \times$ weight in $\mathrm{kg}$ )/3600). ${ }^{16}$ Previous studies have considered height and weight; however, since height and weight are used to calculate BSA and are thus strongly correlated, we elected to report only BSA. Given the homogeneity of ages in our sample (mean (SD) (range): 18.8 (1.0) (17-23) years), we did not assess for age effects.

\section{Statistical analyses}

All analyses were performed using the IBM SPSS statistical package, V.24. Independent samples t-tests were used to assess ARD differences based on race and position. For continuous predictor variables (BSA, HR and LVEF), Pearson bivariate correlations were used. Factors demonstrating a univariate association with a given outcome measure were considered for inclusion in a multiple linear regression.

A primary goal of this study was to determine if ARD normal reference values ${ }^{13}$ for non-athletes applied to our collegiate football athletes. First, we evaluated whether differences existed between the current study's healthy athlete sample and widely used normal values ${ }^{13}$ derived from non-athlete samples for ARD. Cohen's d was calculated as an indicator of the magnitude of the sample differences by extracting the mean, SD and associated sample size data from previously published non-athlete normal references.

We then further investigated demographic-specific influences on the current ARD values. If our prior analyses suggested that a given factor explained significant variance in $\mathrm{ARD}$, then that factor would be used for 
Table 1 General characteristics of studied population of collegiate football players at the time of PPE

\begin{tabular}{|c|c|c|c|c|c|c|c|}
\hline \multirow[b]{3}{*}{ Characteristic } & \multirow{3}{*}{$\begin{array}{l}\mathrm{N}=340 \\
\begin{array}{l}\text { Mean (SD) } \\
\text { (range) }\end{array}\end{array}$} & \multicolumn{2}{|l|}{ Race } & \multirow[b]{3}{*}{ P value* } & \multicolumn{2}{|l|}{ Position group } & \multirow[b]{3}{*}{ P value } \\
\hline & & $\begin{array}{l}\text { Black } \\
(\mathrm{N}=197)\end{array}$ & $\begin{array}{l}\text { White } \\
(\mathrm{N}=142)\end{array}$ & & $\begin{array}{l}\text { Non-linemen } \\
(\mathrm{N}=\mathbf{2 1 4})\end{array}$ & $\begin{array}{l}\text { Linemen } \\
(\mathrm{N}=126)\end{array}$ & \\
\hline & & \multicolumn{2}{|l|}{$\begin{array}{l}\text { Mean (SD) } \\
\text { (range) }\end{array}$} & & \multicolumn{2}{|l|}{$\begin{array}{l}\text { Mean (SD) } \\
\text { (range) }\end{array}$} & \\
\hline Age, years & $\begin{array}{l}18.3(1.0) \\
(17-23)\end{array}$ & $\begin{array}{l}18.2(0.9) \\
(17-21)\end{array}$ & $\begin{array}{l}18.5(1.2) \\
(17-23)\end{array}$ & 0.002 & $\begin{array}{l}18.4(1.1) \\
(17-23)\end{array}$ & $\begin{array}{l}18.2(0.9) \\
(17-21)\end{array}$ & 0.049 \\
\hline Height, cm & $\begin{array}{l}186.7(6.8) \\
(167.6-201.0)\end{array}$ & $\begin{array}{l}186.4(6.5) \\
(167.6-201.0)\end{array}$ & $\begin{array}{l}187.1(7.2) \\
{[170.2-200.7)}\end{array}$ & 0.362 & $\begin{array}{l}183.8(6.1) \\
(167.6-196.9)\end{array}$ & $\begin{array}{l}191.6(4.9) \\
(179.7-201.0)\end{array}$ & $<0.001$ \\
\hline Weight, kg & $\begin{array}{l}102.5(30.0) \\
(61.2-162.2)\end{array}$ & $\begin{array}{l}103.3(21.3) \\
(66.9-162.2)\end{array}$ & $\begin{array}{l}101.4(20.6) \\
(61.2-155.4)\end{array}$ & 0.400 & $\begin{array}{l}90.7(11.0) \\
(61.2-125.9)\end{array}$ & $\begin{array}{l}122.4(18.7) \\
(77.1-162.2)\end{array}$ & $<0.001$ \\
\hline $\mathrm{BSA}, \mathrm{m}^{2}$ & $\begin{array}{l}2.30(0.26) \\
(1.72-2.94)\end{array}$ & $\begin{array}{l}2.30(0.26) \\
(1.84-2.93)\end{array}$ & $\begin{array}{l}2.29(0.26) \\
(1.72-2.94)\end{array}$ & 0.554 & $\begin{array}{l}2.15(0.15) \\
(1.72-2.56)\end{array}$ & $\begin{array}{l}2.55(0.21) \\
(1.97-2.94)\end{array}$ & $<0.001$ \\
\hline Heart rate, bpm & $\begin{array}{l}68.6(11.5) \\
(43-105)\end{array}$ & $\begin{array}{l}67.6(11.6) \\
(43-105)\end{array}$ & $\begin{array}{l}69.9(11.4) \\
(48-104)\end{array}$ & 0.076 & $\begin{array}{l}67.2(11.2) \\
(43-99)\end{array}$ & $\begin{array}{l}71.1(11.9) \\
(51-105)\end{array}$ & 0.004 \\
\hline LVEF & $\begin{array}{l}59.9(5.1) \\
(48-80)\end{array}$ & $\begin{array}{l}59.7(5.0) \\
(50-80)\end{array}$ & $\begin{array}{l}60.1(5.3) \\
(48-78)\end{array}$ & 0.440 & $\begin{array}{l}59.8(5.3) \\
(50-80)\end{array}$ & $\begin{array}{l}59.9(4.8) \\
(48-76)\end{array}$ & 0.938 \\
\hline
\end{tabular}

The 340 participants is a subset of a larger sample $(\mathrm{N}=375)$ with additional echocardiograph measures. No demographic differences were noted between those with $(\mathrm{N}=340)$ and those without $(\mathrm{N}=35)$ available ARD data. Other missing data within the ARD sample $(\mathrm{N})$ : race (1), heart rate (2), LVEF (6).

${ }^{*}$ Demographic characteristic differences assessed using independent samples t-test.

$A R D$, aortic root diameter; LVEF, left ventricle ejection fraction; bpm, beats per minute.

creating more representative reference value tables. We established an a priori requirement of at least a medium effect size association (Cohen's $\mathrm{d}>0.5$ or $\mathrm{r}>0.3$ ) as our criteria for factor-specific reference value tables. We sought also to report our findings of ARD individually and indexed to BSA.

\section{Patient and public involvement statement}

This research was done without patient involvement. Patients were not invited to comment on the study design and were not consulted to develop patient relevant outcomes or interpret results. Patients were not invited to contribute to the writing or editing of this document for readability or accuracy.

\section{RESULTS}

Our sample with ARD measurements included 340 male C-ASF athletes ( $57 \%$ black, $62 \%$ non-linemen). Descriptive statistics are shown for demographic and primary predictor variables for the overall sample stratified by race and position (table 1). shows descriptive statistics for demographic and primary predictor variables for the overall sample stratified by race and position. As expected, linemen had significantly higher height, weight and BSA than non-linemen. ARD values showed a normal distribution (figure 1).

\section{Determination of appropriateness of non-athlete norms}

Comparison of the current sample's ARD values to non-athlete normal reference data ${ }^{13}$ revealed differences with medium or large effects. Our overall C-ASF sample had lower mean ARD values $(\mathrm{d}=1.38$, large effect) than non-athlete normal reference values. We had 10 athletes
(2.7\%) with greater than normal values as defined in a non-athlete population, none of which had an ARD $>40$ $\mathrm{mm}$.

\section{Independent effects of race, position and BSA}

Demographic-specific influences evaluated within our C-ASF study sample showed significant differences within position groups (table 2). No race differences in ARD were observed. For position, linemen exhibited significantly higher ARD ( $\mathrm{d}=0.55$, medium effect) than non-linemen. As expected, BSA correlated very strongly

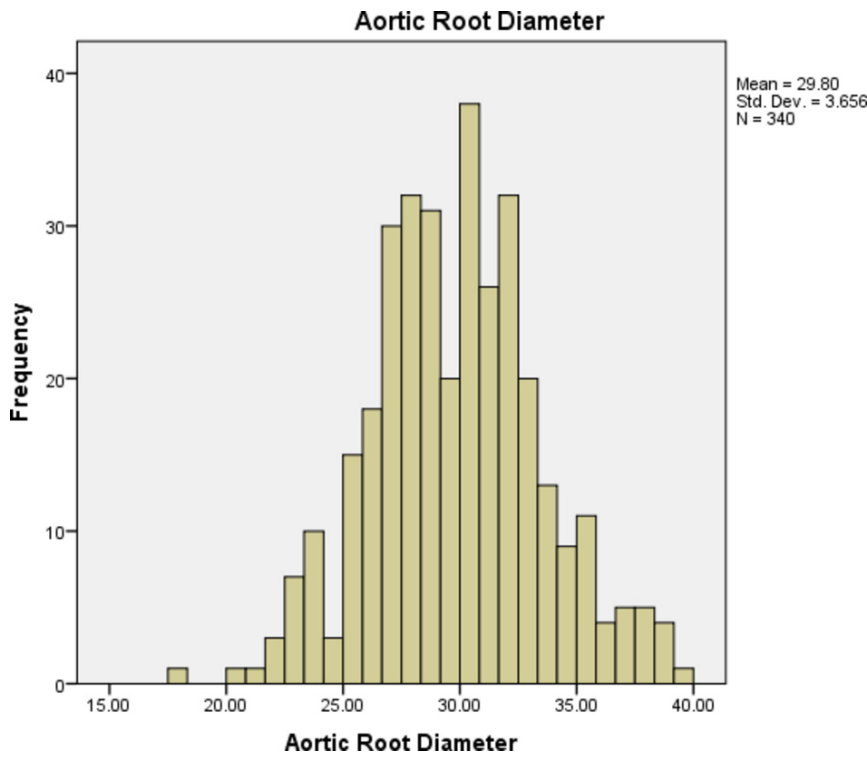

Figure 1 Histogram of aortic root diameter at the sinuses of Valsalva distribution in collegiate football athletes. 
Table 2 Echocardiogram characteristics of collegiate football players

\begin{tabular}{|c|c|c|c|c|c|c|c|c|c|}
\hline \multirow[b]{3}{*}{$\begin{array}{l}\text { Echo metric } \\
(\mathrm{mm})\end{array}$} & \multirow{3}{*}{$\begin{array}{l}\text { Overall } \\
\text { Mean (SD) } \\
\text { (Range) }\end{array}$} & \multicolumn{2}{|l|}{ Race } & \multirow{2}{*}{$\begin{array}{l}\text { Mean } \\
\text { difference }\end{array}$} & \multirow[b]{2}{*}{ Effect size } & \multicolumn{2}{|c|}{ Position group } & \multirow{2}{*}{$\begin{array}{l}\text { Mean } \\
\text { difference }\end{array}$} & \multirow[b]{2}{*}{ Effect size } \\
\hline & & Black & White & & & Non-linemen & Linemen & & \\
\hline & & \multicolumn{2}{|c|}{$\begin{array}{l}\text { Mean (SD) } \\
\text { (Range) }\end{array}$} & $(95 \% \mathrm{Cl})$ & Cohen's d & $\begin{array}{l}\text { Mean (SD) } \\
\text { (range) }\end{array}$ & & $(95 \% \mathrm{Cl})$ & Cohen's d \\
\hline ARD & $\begin{array}{l}29.8(3.7) \\
(18.0-39.7)\end{array}$ & $\begin{array}{l}29.8 \\
(3.9) \\
(18.0- \\
39.7)\end{array}$ & $\begin{array}{l}29.8 \\
(3.3) \\
(23.0- \\
39.0)\end{array}$ & $\begin{array}{l}0.02 \\
(-0.8 \text { to } 0.7)\end{array}$ & 0.01 & $\begin{array}{l}29.1(3.4) \\
(20.6-39.7)\end{array}$ & $\begin{array}{l}31.0(3.7) \\
(18.0-39.0)\end{array}$ & $\begin{array}{l}2.0 \\
\text { (1.1 to } 2.8)\end{array}$ & $0.55^{\star}$ \\
\hline
\end{tabular}

Sample size (N) for ARD: overall (340), Black (197), White (142), non-linemen (214), linemen (126).

${ }^{*} \mathrm{P}<0.001$.

ARD, aortic root diameter.

with height $(\mathrm{r}=0.736, \mathrm{p}<0.001)$ and weight $(\mathrm{r}=0.991$, $\mathrm{p}<0.001)$; therefore, only BSA effects were further evaluated. Similar results with demographic associations were found when using BSA-indexed scores instead of raw scores (table 3).

Associations between echocardiogram values and continuous predictor variables (BSA, HR and LVEF) were explored. BSA correlated positively with ARD ( $r=0.379$, $\mathrm{p}<0.001$, medium effect). No associations between HR or LVEF and ARD were observed.

Only position and BSA (not race) were significantly associated with ARD. The $\chi^{2}$ analyses indicated no association between race and position $\left(\chi^{2}(1,375)=0.196\right.$, $\mathrm{p}=0.658)$. However, position and BSA correlated very strongly $(\mathrm{r}=0.750, \mathrm{p}<0.001$, large effect), suggesting likely multicollinearity effects. The decision was made to stratify normal reference values by BSA rather than position. We based this decision on previous research highlighting the importance of BSA in cardiac measurement outcomes, and investigator consensus that BSA more appropriately characterises the 'risk' for differences in ARD than the position played by the participant (ie, a non-lineman with a high BSA is presumably at the same 'risk' as a lineman with equivalent BSA).

\section{Reference values for collegiate football athletes stratified by BSA group}

BSA was transformed into a categorical factor based on 1-SD cut-points in the BSA distribution, creating below average $(\mathrm{Z}<-1)$, average $(-1<\mathrm{Z}<1)$ and above average
$(\mathrm{Z}>1)$ reference groups. Analyses of variance confirmed that the BSA groupings preserved the linear association between BSA and ARD $(\mathrm{F}(2,337)=18.984, \mathrm{p}<0.001)$, with significant mean differences in the expected direction (below average $<$ average $<$ above average). Additional comparisons to non-athlete normal ranges were made using the BSA subgroups in our C-ASF athlete sample (combined linemen and non-linemen).

Tables 4 and $5^{413}{ }^{17}$ show ranges for 'normal' and possible 'abnormal' cutoffs for each normal reference group, using both raw ARD values, as well as index scores calculated by dividing each participant's measurements by their BSA. Values were determined to be 'normal' if they fell before the 95th percentile in the distribution, or all values with a Z-score less than 1.6. 'Mildly abnormal', 'moderately abnormal', and 'severely abnormal' were defined by values falling in the 95th-98th percentile $(1.6<\mathrm{Z}<2.0), 98$ th-99th percentile $(2.0<\mathrm{Z}<2.5)$ and $>99$ th percentile $(Z>2.5)$, respectively.

Of note, despite using the BSA index score in the current sample, we still observed the same linear association between BSA group and ARD measurements $(p<0.001)$, suggesting BSA group-specific normal reference values remain warranted even when using index scores that attempt to account for BSA differences. We once again compared our C-ASF sample to non-athlete normal reference data, this time using BSA-indexed scores. Non-athlete values were much higher than our overall football athlete sample for ARD/BSA $(d=2.18$,

Table 3 Echocardiogram characteristics of collegiate football players indexed to BSA

\begin{tabular}{|c|c|c|c|c|c|c|c|c|c|}
\hline \multirow{3}{*}{$\begin{array}{l}\text { Echo } \\
\text { metric/ } \\
\text { BSA (mm/ } \\
\left.\mathrm{m}^{2}\right)\end{array}$} & \multirow[b]{2}{*}{ Overall } & \multicolumn{2}{|l|}{ Race } & \multirow[b]{2}{*}{$\begin{array}{l}\text { Mean } \\
\text { difference }\end{array}$} & \multirow[b]{2}{*}{ Effect size } & \multicolumn{2}{|c|}{ Position group } & \multirow[b]{2}{*}{$\begin{array}{l}\text { Mean } \\
\text { difference }\end{array}$} & \multirow[b]{2}{*}{ Effect size } \\
\hline & & Black & White & & & $\begin{array}{l}\text { Non- } \\
\text { linemen }\end{array}$ & Linemen & & \\
\hline & $\begin{array}{l}\text { Mean (SD) } \\
\text { (range) }\end{array}$ & $\begin{array}{l}\text { Mean (SD) } \\
\text { (range) }\end{array}$ & & (95\% Cl) & Cohen's d & $\begin{array}{l}\text { Mean (SD) } \\
\text { (Range) }\end{array}$ & & (95\% Cl) & Cohen's d \\
\hline ARD & $\begin{array}{l}13.1(1.7) \\
(7.6-18.2)\end{array}$ & $\begin{array}{l}13.0(1.8) \\
(7.6-18.2)\end{array}$ & $\begin{array}{l}13.1(1.6) \\
(8.9-16.9)\end{array}$ & $\begin{array}{l}0.11 \\
(-0.48 \text { to } \\
0.25)\end{array}$ & 0.06 & $\begin{array}{l}13.6(1.6) \\
(8.4-18.2)\end{array}$ & $\begin{array}{l}12.3(1.6) \\
(7.6-16.3)\end{array}$ & $\begin{array}{l}1.3 \\
(0.97 \text { to } \\
1.66)\end{array}$ & $0.81^{*}$ \\
\hline
\end{tabular}

Sample size (N) for ARD: overall (340), Black (197), White (142), non-linemen (214), linemen (126).

${ }^{\star} \mathrm{P}<0.001$.

ARD, aortic root diameter; BSA, body surface area. 
Table 4 ARD reference values by BSA group

\begin{tabular}{|c|c|c|c|c|c|}
\hline \multirow{3}{*}{$\begin{array}{l}\text { Echo measure } \\
(\mathrm{mm})\end{array}$} & \multirow{3}{*}{$\begin{array}{l}\begin{array}{l}\text { Overall } \\
\text { sample }\end{array} \\
1.72-2.94 \mathrm{~m}^{2}\end{array}$} & \multicolumn{3}{|c|}{ BSA reference group } & \multirow{3}{*}{$\begin{array}{l}\text { General } \\
\text { population male } \\
\text { norms } 41317\end{array}$} \\
\hline & & Below average & Average & Above average & \\
\hline & & $1.72-2.05 \mathrm{~m}^{2}$ & $2.06-2.57 \mathrm{~m}^{2}$ & $2.58-2.94 \mathrm{~m}^{2}$ & \\
\hline \multicolumn{6}{|l|}{ ARD } \\
\hline Normal & $<35.6$ & $<32.4$ & $<35.5$ & $<37.9$ & $<38.8$ \\
\hline Mildly abnormal & $35.6-37.1$ & $32.4-33.5$ & $35.5-36.9$ & $37.9-39.4$ & $38.8-40.0$ \\
\hline $\begin{array}{l}\text { Moderately } \\
\text { abnormal }\end{array}$ & $37.2-38.9$ & $33.6-35.0$ & $37.0-38.7$ & $39.5-41.2$ & $40.1-41.5$ \\
\hline Severely abnormal & $>38.9$ & $>35.0$ & $>38.7$ & $>41.2$ & $>41.5$ \\
\hline
\end{tabular}

Our definitions for BSA reference groups: mildly abnormal: 95-98th percentile or 1.6<Z<2.0; moderately abnormal: 98-99th percentile or $2.0<Z<2.5$; severely abnormal: $>99$ th percentile or $Z>2.5$.

.ARD, aortic root diameter; BSA, body surface area.

large effect), which was consistent across the Below Average $(\mathrm{d}=1.52$, large effect), Average $(\mathrm{d}=2.17)$, and Above Average BSA groups ( $\mathrm{d}=3.12$, large effect).

It is worth noting that both the raw ARD measurement and ARD/BSA index scores were found to be higher in non-athlete normal reference data.

\section{DISCUSSION}

We found that for C-ASF players' echocardiogram values at the time of PPE, using the non-athlete reference values ${ }^{13}$ for the upper limit of normal may still be applicable, even though they show a different normal distribution than non-athletes. The ARD distribution for our C-ASF athlete sample was lower than for non-athletes which was an unexpected finding. Since the medical concern is with elevated ARD values, the non-athlete upper limit of normal reference value $(37 \mathrm{~mm})^{13}$ may still be appropriate, while at values above that BSA should be considered in the interpretation.

Aortic root enlargement is of interest in athletes as it is associated with Marfan's syndrome and can lead to aortic dissection and sudden death. The Marfanoid habitus can mimic some beneficial athletic features including tall stature and long arms. Height, weight and specific type of sport participation have been shown to have the greatest impacts on ARD. ${ }^{18}$ Our data showed linemen exhibited significantly higher ARD than non-linemen. Previous studies have recommended $\geq 38 \mathrm{~mm}$ and $\geq 40$ $\mathrm{mm}$ as cut-off values for ARD in non-athletes ${ }^{13}$ and athletes ${ }^{18}$ respectively. In our sample of C-ASF athletes at the beginning of their collegiate careers, we found only 10 athletes $(2.7 \%)$ had an aortic root of $\geq 38 \mathrm{~mm}$ and no athletes in this cohort had an aortic root of $\geq 40$ $\mathrm{mm}$. Therefore, the non-athlete upper limit of normal reference value $>37 \mathrm{~mm}$ may be appropriate when interpreting ARD values. There was no evidence of aortic root adaptations to exercise that exceeded predefined norms in this C-ASF sample. A meta-analysis by Iskandar and Thompson demonstrated a weighted mean ARD of $31.6 \mathrm{~mm}(95 \%$ CI 30.2 to 33.1$)$ at the sinus of Valsalva, ${ }^{19}$ compared with a diameter of $29.8 \mathrm{~mm}$ (95\% CI 29.4 to 30.2 ) in our population.

It is possible that since the timing of our screening is prior to engaging in the intensity of training and conditioning associated with C-ASF, these values do not yet represent the possible adaptive changes specific to collegiate-level athletics. Progressive aortic dilation has been shown in a cohort of strength trained athletes as duration of training increases, with duration of training correlating significantly with aortic root size. ${ }^{8}$ Additionally, most studies evaluating aortic root dimensions are in athletes who are older than our college population. ${ }^{71120}$ It is possible that aortic remodelling may occur as a product of prolonged, intense training in larger individuals. However, Pelliccia et al followed several athletes with dilated aortas $>40 \mathrm{~mm}$ and without stigmata of Marfan's syndrome over several years after conclusion of their athletic careers and found that the largest increases in aortic dimension in athletes tends to occur in midlife as opposed to years with high volumes of training. ${ }^{6} \mathrm{~A}$ recent study of 3781 young athletes (age: $19 \pm 5.9$ years) had $5 \pm 1.5$ years longitudinal follow-up of those athletes with an enlarged aortic diameter and found no progressive enlargement of the aortic diameter during that time. ${ }^{21}$ Their cohort had a larger mean ARD compared with controls and did not include American-style football athletes. ${ }^{21}$ This discrepancy in findings regarding the aetiology of increased ARD in some athletes presents opportunity for further research to better understand the timing of aortic remodelling and determine if there are clinical consequences to progressive dilation.

Our findings of ARD values at the time of PPE being lower than non-athlete controls contrasts with our findings of significantly larger left ventricular end diastolic diameter (LVEDD) and interventricular septal diameter (IVSD) in the same population of collegiate football athletes. ${ }^{22}$ It is possible that the mostly muscular areas of the heart (including LVEDD and IVSD) have non-pathological training adaptations, while areas containing mostly connective tissue do not experience similar adaptations in adolescence. 

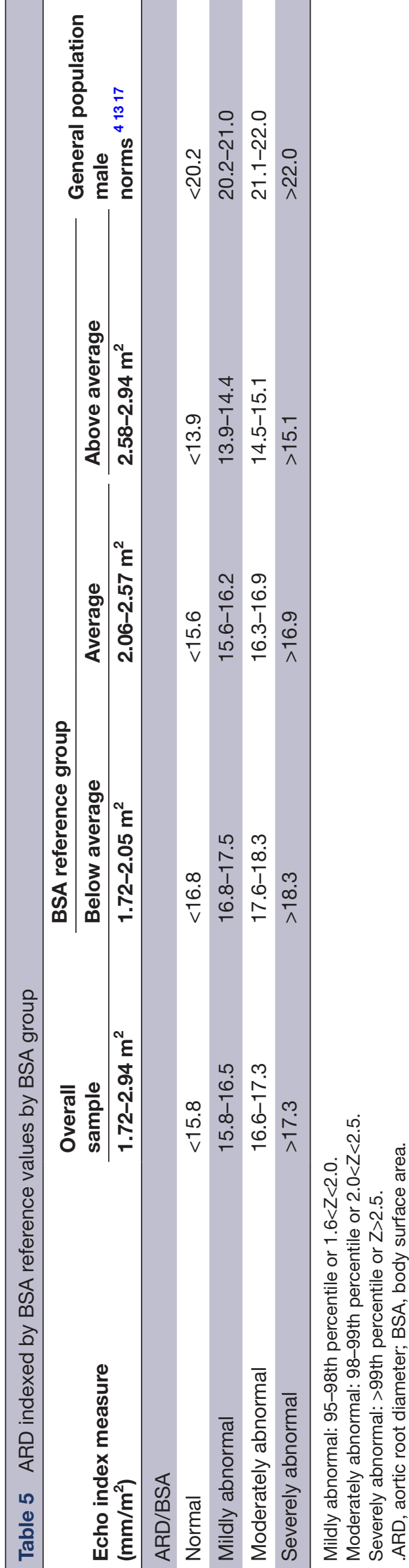

\section{CONCLUSIONS}

The results of this study provide normal reference data for C-ASF players at the time of PPE for ARD at the sinuses of Valsalva. Our results suggest that non-athlete ARD abnormal cut-off of $37 \mathrm{~mm}$ may be applicable. Our analysis shows BSA to have the most significant association with ARD values. ARD values in C-ASF athletes approaching upper limits of non-athlete norms should be approached with caution and further evaluated as we did not find larger ARD to be typical in our studied C-ASF population.

\section{Study limitations}

Although the study was performed on a large sample of C-ASF athletes, it did not include athletes from races other than blacks and whites and may not be applicable to other races. Additionally, both institutions compete in NCAA Division I Football Bowl Subdivision and our results may not apply to other competition levels. The echocardiograms were obtained at the time of matriculation so do not represent adaptive changes seen from playing collegiate football. Therefore, our results may not apply to different time points in football participation including youth, end of college career or professional. Measurements of ARD were made at the Sinuses of Valsalva, which represents only one segment of potential dilation of the thoracic aorta. However, this site was chosen as it is the location of enlargement used in the diagnosis of Marfan's syndrome ${ }^{23}$ which is the primary cause of aortic dilation in this population. The presence of bicuspid aortic valve was also not reported, which can also influence interpretation of aortic root dimensions. The echocardiogram measurements analysed were taken from those interpreted clinically and were not over-read by a single cardiologist for research purposes. Multiple cardiologists contributed to the interpretation of studies; however, three cardiologists read $93 \%$ of the echocardiograms. These factors may lead to some inherent variability in the measurements. Other limitations include the lack of a comparison group of non-athletes with similar biometrics to this C-ASF cohort, as well as the study's cross-sectional design which excluded follow-up for those athletes with cardiac variables at the outer edges of distribution, and the use of statistically derived abnormal cut-off values. Longitudinal studies are needed to look at athletes with aortic root dilations to see if their presence correlates with an increased cardiovascular risk over time.

Acknowledgements The authors wish to thank Monica Towns for her help with obtaining informed consents, data collection and entry. The corresponding author wishes to thank Robert Brown for his technical assistance.

Contributors FR, JC and KME contributed to planning, conduct and reporting. SC, $\mathrm{KH}, \mathrm{BMA}, \mathrm{MD}$ and JS contributed to review of the manuscript.

Funding This work was supported in part by The American Medical Society for Sports Medicine (AMSSM) Foundation Research Grant 2016 awarded to KME, and the University of Florida REDCap utilizes the NIH National Center for Advancing Translational Sciences (NCATS) grant UL1 TR000064. Publication of this article was funded by the University of Georgia Health Center. 
Competing interests JS is a part time consultant in the capacity of quality assurance technologist for Athletic Heart, LLC.

Patient consent for publication Not required.

Ethics approval The University of Florida Institutional Review Board and the University of Georgia Institutional Review Board.

Provenance and peer review Not commissioned; externally peer reviewed.

Data sharing statement All data relevant to the study are included in the article or uploaded as supplementary information.

Open access This is an open access article distributed in accordance with the Creative Commons Attribution Non Commercial (CC BY-NC 4.0) license, which permits others to distribute, remix, adapt, build upon this work non-commercially, and license their derivative works on different terms, provided the original work is properly cited, appropriate credit is given, any changes made indicated, and the use is non-commercial. See: http://creativecommons.org/licenses/by-nc/4.0/.

\section{REFERENCES}

1. Terlep S. Worried about heart defects, some NCAA schools take action. Wall Street Journal 20152015.

2. Drezner JA, Owens DS, Prutkin JM, et al. Electrocardiographic screening in national collegiate athletic association athletes. Am J Cardiol 2016;118:754-9.

3. Braverman AC, Harris KM, Kovacs RJ, et al. Eligibility and Disqualification recommendations for competitive athletes with cardiovascular abnormalities: Task Force 7: aortic diseases, including Marfan syndrome: a scientific statement from the American Heart Association and American College of cardiology. J Am Coll Cardiol 2015;66:2398-405

4. Roman MJ, Devereux RB, Kramer-Fox R, et al. Two-dimensional echocardiographic aortic root dimensions in normal children and adults. The American Journal of Cardiology 1989;64:507-12.

5. Reed CM, Richey PA, Pulliam DA, et al. Aortic dimensions in tall men and women. Am J Cardiol 1993;71:608-10.

6. Pelliccia A, Di Paolo FM, Quattrini FM. Aortic root dilatation in athletic population. Prog Cardiovasc Dis 2012;54:432-7.

7. D'Andrea A, Cocchia R, Riegler L, et al. Aortic root dimensions in elite athletes. Am J Cardiol 2010;105:1629-34.

8. Babaee Bigi MA, Aslani A. Aortic root size and prevalence of aortic regurgitation in elite strength trained athletes. Am J Cardiol 2007;100:528-30.

9. Kinoshita N, Mimura J, Obayashi C, et al. Aortic root dilatation among young competitive athletes: echocardiographic screening of 1929 athletes between 15 and 34 years of age. Am Heart $J$ 2000;139:723-8.

10. Engel DJ, Schwartz A, Homma S. Athletic cardiac remodeling in US professional basketball players. JAMA Cardiol 2016;1:80-7.

11. Davis CK, Dyar DA, Vargas LA, et al. Cardiovascular and musculoskeletal assessment of elite us volleyball players. Clin J Sport Med 2015;25:1-50.

12. Athletic heart. Available: www.athletic-heart.com [Accessed 10 May 2018].

13. Lang RM, Badano LP, Mor-Avi V, et al. Recommendations for cardiac chamber quantification by echocardiography in adults: an update from the American Society of echocardiography and the European association of cardiovascular imaging. J Am Soc Echocardiogr 2015;28:1-39.

14. Association UoFA. Football roster, 2016. Available: floridagators.com

15. Association. UoGA. football roster, 2016. Available: http:// georgiadogs.com/2016

16. Mosteller RD. Simplified calculation of body-surface area. $N$ Engl $J$ Med 1987;317.

17. Hiratzka LF, Bakris GL, Beckman JA, et al. 2010 ACCF/AHA/AATS/ ACR/ASA/SCA/SCAI/SIR/STS/SVM guidelines for the diagnosis and management of patients with thoracic aortic disease: a report of the American College of cardiology Foundation/American Heart Association Task Force on practice guidelines, American Association for thoracic surgery, American College of radiology, American Stroke Association, society of cardiovascular Anesthesiologists, Society for cardiovascular angiography and interventions, society of interventional radiology, society of thoracic Surgeons, and Society for vascular medicine. Circulation 2010;121:e266-369.

18. Pelliccia A, Di Paolo FM, De Blasiis E, et al. Prevalence and clinical significance of aortic root dilation in highly trained competitive athletes. Circulation 2010;122:698-706.

19. Iskandar A, Thompson PD. A meta-analysis of aortic root size in elite athletes. Circulation 2013;127:791-8.

20. Boraita A, Heras M-E, Morales F, et al. Reference values of aortic root in male and female white elite athletes according to sport. Circ Cardiovasc Imaging 2016;9.

21. Gati S, Malhotra A, Sedgwick C, et al. Prevalence and progression of aortic root dilatation in highly trained young athletes. Heart 2019.

22. Edenfield KM, Reifsteck F, Carek S, et al. Echocardiographic measurements of left ventricular end-diastolic diameter and interventricular septal diameter in collegiate football athletes at preparticipation evaluation referenced to body surface area. BMJ Open Sport Exerc Med 2019;5.

23. Loeys BL, Dietz HC, Braverman AC, et al. The revised Ghent nosology for the Marfan syndrome. J Med Genet 2010;47:476-85. 